\title{
Of metaphors and literalization: Reconceptualizing scaffolding in Language \\ Teaching
}

\author{
De métaphores et de littéralisation: \\ Reconceptualiser un échafaudage dans \\ l'enseignement de la langue
}

\section{De metáforas y literalización: reconceptualizando el andamiaje en la enseñanza de idiomas}

\section{Gabriel H. Díaz Maggioli}

The New School University, United States

\begin{abstract}
The metaphor of scaffolding is ubiquitous in the field of education and that of Language Teaching, in particular. However, the term has become literalized, thus losing its original meaning, and is now an umbrella term encompassing various forms of teacher intervention. Added to this, the metaphor has come under extended criticism as a consequence of the spread of Sociocultural Learning Theory. This paper explores the metaphor of scaffolding and attempts to validate it as a legitimate form of mediation within the sociocultural construct of Zone of Proximal Development by promoting a reconceptualization of the term, in light of alternative definitions. Implications for language teaching and language teacher education are highlighted and new perspectives advanced.
\end{abstract}

Key Words: scaffolding; zone of proximal development; sociocultural learning theory; teaching; learning.

\section{RESUMEN}

La metáfora del andamiaje está omnipresente en el campo de la educación y en el de la enseñanza de idiomas, en particular. Sin embargo, el término se ha literalizado perdiendo así su sentido original, y ahora es un término que abarca diversas formas de intervención docente. Sumado a esto, esta teoría ha sido objeto de críticas como consecuencia de la difusión de la 
teoría del aprendizaje sociocultural. Este trabajo explora la metáfora del andamiaje y los intentos para validarla como una forma legítima de la mediación dentro de la construcción sociocultural de la Zona de Desarrollo Próximo, promoviendo una reconceptualización del término a la luz de las definiciones alternativas. Se destacan las implicaciones para la enseñanza de idiomas y la formación del profesorado de idiomas y nuevas perspectivas avanzadas.

Descriptores: andamiaje; zona de desarrollo próximo; teoría del aprendizaje sociocultural; enseñanza; aprendizaje.

\section{RÉSUMÉ}

La métaphore de l'échafaudage est omniprésente dans le domaine de l'éducation et en particulier dans celui de la langue. Cependant le terme est devenu littéralisé, perdant ainsi son sens originel, et est maintenant un terme général qui recouvre diverses formes d'interventions par les enseignants. Ajouté à cela, la métaphore a subi une critique multirisque comme conséquence de la dissémination de la Théorie de l'apprentissage socioculturel. Ce papier explore la métaphore de l'échafaudage et tente de la confirmer comme forme légitime de médiation dans un concept socioculturel constructiviste de Zone de développement proximal en promouvant une reconceptualisation du terme à la lumière de définitions alternatives. Les implications pour l'enseignement de la langue et la formation des enseignants de langue sont soulignées et de nouvelles perspectives avancées.

Mots clés: echafaudages; zone proximale de développement; théorie de l'apprentissage socioculturel; enseignement; apprendre.

\section{Introduction}

$\mathrm{T}$ HE LANGUAGE TEACHING (LT) PROFESSION has evolved under the shadow of other disciplines. LT practices have been influenced by input from such disparate domains of knowledge as Anthropology, Linguistics, Pedagogy, Psychology, and even Computer Science.

In this context, it is not surprising that new developments are often misconstrued upon partial understandings of concepts only accessible to full-fledged members of the discipline in which they were born. Hence, these concepts often lose their original (and intended) meaning, and soon become an umbrella term for various practices. In other words, as LT assimilates conceptual fodder from other disciplines in attempts to explain particular features of theory and/or praxis, the original concepts become literalized - that is, they gain new and highly situated meanings, which, in many cases, depart radically from the initial elaboration of the concept.

One theoretical construct that has become literalized in the field of Education in general, and LT in particular, is the metaphor of scaffolding. In its original incarnation, scaffolding is defined as a "process that enables a child or novice to solve a problem, carry out a task or achieve a goal which would be beyond his [sic] unassisted efforts" (Wood et al., 1976, p. 90). Seen in this light, it could be argued that scaffolding can be a useful metaphor for a variety of teacher interventions, since it appears to provide a justification for principled instruction at a time when the discourse of the profession veers toward student-centered and problem-solving pedagogical models.

It is no surprise then, that, since its inception, scaffolding has gained widespread adherence in various educational realms. In fact, it has become an umbrella metaphor 
for an assortment of educational practices ranging from tutoring to facilitation and even direct instruction (Verenikina, 2004).

However, the most problematic issue with the metaphor is that it is readily identified as a form of mediation within Vygotsky's (1978) construct of Zone of Proximal Development (ZPD). Various authors (Gibbons, 2003; Sharpe, 2011; Walqui \& van Lier, 2010) sustain that the metaphor can be successfully applied to the interventions that teachers and others make within the learners' ZPD. This was defined by Vygotsky (1978) as "the distance between the actual development level as determined by independent problem solving and the level of potential development as determined through problem solving under adult guidance or in collaboration with more capable peers" (p. 86, emphasis in the original).

On the surface, the definitions of both constructs seem to be compatible and even comparable. In both, reference is made to a purposeful intervention by a more knowledgeable other (adult or peer) who mediates the solution of a problem, encapsulating a learning move on the part of the learner/novice. Likewise, both refer to two distinct levels of performance (assisted and unassisted) as well as to a "distance" between current and future performance.

However, various critics (Chaiklin, 2003; Poehner, 2010; Swain et al., 2011; Verenikina, 2004) have pointed out the inadequacy of such a simplistic match, and warn educators of an inherent contradiction in readily associating one with the other. According to these authors, the fallacy of the compatibility argument lies in an unreflective and decontextualized understanding of the ZPD and, more importantly, Vygotsky's own theory of child development. Arguments in favor of demystifying the illusion of compatibility range from the assumption that ZPD is an attempt at explaining development within a staged theory of child development and not as a metaphor for learning (Chaiklin, 2003), to the lack of actual dialogic activity in the original concept of scaffolding (Swain et al., 2011).

This controversy notwithstanding, it should be acknowledged that "the concepts of 'scaffolding' and ZPD have become important guiding ideas in education because within them are embedded a psycho-social model of teaching and learning" (Bliss et al., 1996, p. 38). In the field of LT, in particular, both constructs have become ubiquitous and readily associated. Moreover, in recent years, a plethora of teacher education materials have made explicit reference to scaffolding as a valid way of mediating learning efforts in the ZPD (Gibbons, 2002; Shrum \& Glisan, 2010; Walqui \& van Lier, 2010). In the current reality, where the field is becoming heavily influenced by Sociocultural Theory (Johnson, 2009), it makes sense to explore the dichotomy perceived by some critics in order to shed light on how the terms can best be interpreted for the purposes of teacher education and teacher development - but also, more importantly, how they stand in relation to good teaching.

\section{The Mediated Learning Experience}

Vygotsky (1978) introduced the concept of mediation to account for ways in which 
individuals interact with the world around them and thus learn. Interactions between the individual and the world are often mediated by the use of human-made tools (material and symbolic). These material and symbolic artifacts have the potential to mediate but, "until used as such, they offer only affordances and constraints to an individual" (Swain et al., 2011, p. 2).

Perhaps the person who has elaborated the most on the characteristics of the mediated learning experience (MLE) is Reuven Feuerstein (Feuerstein et al., 1980), who bases his Instrumental Enrichment (IE) Program on the premise that, given suitable mediation, all individuals have the potential to learn and develop. To this author, all behavior is both culturally determined and situationally triggered. Within IE, adult mediation of children's learning stems from a perceived need by adults to shape the child's behavior so that it conforms to the historical (present, past, and future) conditions of society. In other words, MLE is a form of "group supported behavior oriented towards preserving cultural continuity” (Feuerstein et al., 1980, p. 21).

Feuerstein's construct is a further elaboration of the notion of ZPD in which interaction between a child and a more capable other results in learning gains for both the mediator and the mediated, who pursue a particular goal whose realization is in the future. However, not all interactions can be termed MLEs. There are various characteristics an interaction should embody in order to effectively provide mediation: intentionality and reciprocity, transcendence beyond the "here-and-now," meaningfulness, contingent multimodality, and a social-to-individual orientation.

\section{Intentionality/Reciprocity}

According to Poehner and Lantolf (2005), "intentionality refers to the adult's deliberate efforts to mediate the world, an object in it or an activity for the child" (p. 241). Both mediator and mediated purposefully engage in interaction and invest in it through dedicated attention, focus, and purpose. This intentionality has two dimensions, one referring to the object and the other referring to the child. Through the engagement of the adult, the object is transformed for the child so that it is not merely registered but "noted and marked" (Mason, 2002, p. 33). It should be highlighted that the purpose of the interaction is not to effect changes on the perception of the object, but on "the child's cognitive processes that are the primary target of mediated interaction, and this too, should be made clear to the child" (Kozulin, 1998, p. 66).

Intentionality implies that the adult consciously focuses on the child's level of performance, their attention, and learning moves (to include mistakes), as well as the strategies the child uses to approach the solution of the problem, and responds to these by progressively adapting aspects of the object so that the child's attention is geared toward the purpose at hand. Intentionality is what distinguishes "the MLE from the haphazard, incidental nature of traditional instruction" (Poehner \& Lantolf, 2005 , p. 241). Most relevant is the fact that the interaction within this MLE promotes a change in all three participating variables: the object/task, the mediator, and the mediated, affecting the activity in a systemic fashion. 
It should be noted, however, that these two characteristics of MLE act in unison and cannot be separated. It is the intention to mediate/gain mediation that prompts the reciprocity of the interaction, which, in turn, reinforces its intentionality.

\section{Transcendence}

For an interaction to be classified as an MLE, it should transcend the child's hereand-now so that, while providing support for the task at hand, it does not lose sight of the culturally determined future for which mediation is being made available. The MLE is thus a means - and not an end in itself - to attain a certain cultural goal whose realization is not in the task at hand, but in the future potential development. Both the work of Vygotsky $(1978 ; 1986)$ and Feuerstein et al. (1980) make reference to the need to go beyond the specific subject or task at hand to become a means for the reconstruction and consequent expansion of cognitive structure. Most of the mediation in MLE stems from culture-specific historical scripts passed on from generation to generation (such as traditions, rituals, games, and tales). The purpose of these scripts - generally applied in a subconscious and non-deliberate way by mediators - is the transmission of culture from generation to generation. Hence, the purpose of the MLE is to provide ways for the child to become a full-fledged member of their community in the future by acting upon the here-and-now, hence the transcendence aspect of the interaction. For this reason, while the child is naturally limited by the stimuli afforded by the environment, having access to MLE allows him to access the past and future, which constitute the history of the practices of the community.

This brings about another relevant argument regarding the role that the content of the interaction plays in shaping MLE. Both Vygotsky and Feuerstein et al. developed their theory in the context of child development, and, in particular, children who exhibited some sort of learning impairment. In both conceptualizations, the content of the activity is incidental with the focus resting on the efforts made by the adult mediating the child's learning. In this scenario, intentionality and transcendence do not apply to the object or the task at hand, but to the opportunities for cognitive modifiability that the interaction affords and that are guided by a future state of development co-constructed by participants in the here-and-now. As Poehner and Lantolf (2005) explain, "true development transcends any specific tasks and manifests itself in a variety of ways under a multitude of different conditions" (p. 241).

\section{Meaningfulness}

While MLE does not seem to rest on the elaboration of specific contents, at least during childhood, ${ }^{1}$ one further prerequisite for an interactive activity to be considered an MLE is that it should be imbued with meaning. Unless meaning is coconstructed and negotiated, the whole interactive experience may be perceived by the child as a "mere sequence of strange behavioral acts - devoid of purpose and affective 
investment" (Kozulin, 1998, p. 67). It is the mediator's role to infuse meaning into the stimuli, events, or information so that it becomes mutually meaningful (p. 67).

The meaning to be constructed and negotiated through participation in the interaction also helps fulfill the other two characteristics of the MLE. In terms of intentionality/reciprocity, there is purposeful engagement of mediator and mediated in this elaboration and negotiation of meaning around a task, not for the purpose of solving the task alone, but because the meaning-making process accessible through MLE allows the mediated individual to move forward - through learning - in their development. Hence, the task itself is incidental and serves as the turf where new cognitive structures have the potential of being established.

While Vygotsky $(1978 ; 1986)$ and Kozulin (1998) considered these three to be the key characteristics of MLE, a closer look at the work of Feuerstein et al. (1980) provides us with two other important characteristics of MLE, which may help us build a stronger theoretical framework for our analysis: contingent multimodality and social-to-individual orientation to learning.

\section{Contingent multimodality}

While it can rightfully be claimed that language is "the most economic and efficient transmitter of learning" (Feuerstein et al., 1980, p. 24), MLE makes use of other semiotic tools (or contingent modalities) for the intentional making of meaning. These include gesture, mimicry, observation, and behaviors in general (such as learning strategies and a disposition to put metacognition at play). Gibbons (2003) coined the term "message abundancy" (p. 267) to refer to these various semiotic systems that support activity and understanding in scaffolded situations. The acknowledgement of these multiple contingencies as valid means for the establishment of MLE bears particular relevance to the task of language teaching, where linguistic interactions are limited by the existing gap in language proficiency between mediator and mediated.

More recently, and referring specifically to the activity of teaching, Sharpe (2006) reinforced this characteristic of MLE by saying that "the construction of the ZPD occurs not only through the semiotic modality of language that enables students to actively participate in a conversation with the teacher, texts and peers, but also through other semiotic modalities such as body language, voice, diagrams, and activity" (p. 229).

This acknowledgement also imbues MLE with a universal nature, in that it appears to be a pervasive form of cultural reproduction irrespective of available technologies or semantic encoding (Feuerstein et al., 1980). Hence, the potential for cognitive modifiability that engagement in MLE brings about seems to validate the construct as a development-oriented form of interaction in those situations where language cannot play a particularly central mediating role. 


\section{Social-to-individual orientation to learning}

MLE is a two-dimensional enactment of meaningful intentionality by which a culture ensures its continuity (Feuerstein et al., 1980). This element of cultural transmission is a particularly relevant one, because it tallies with the transcendence aspect of MLE in that it enables "the individual to transcend the here and now, to adapt to new modes of functioning, and to develop new patterns of behavior appropriate to new situations. In other words, MLE produces in the organism a propensity to learn how to learn, by equipping the organism with the tools necessary for this faculty" (Feuerstein et al., 1980, p. 25).

This bears particular relevance for language teaching in light of developments in the field, which call for the explicit teaching of learning strategies oriented at learner independence. Models such as the Cognitive Academic Language Learning Approach (Chamot, 2009) call for the explicit teaching of metacognitive, cognitive, and social strategies (which could be termed pedagogical mental tools) to mediate the language learners' development of Cognitive Academic Language Proficiency.

\section{A theoretical framework for assessing "Scaffolding"}

The reasons those against considering scaffolding a valid form of mediation in the ZPD waive are as varied as the researchers who have engaged in this process of analysis. For example, Swain et al. (2011) observe that the metaphor of scaffolding is flawed in two ways. First, as strictly defined in its 1976 original coinage, the tutoring action described by Wood et al. can be interpreted as a uni-directional act dominated by the mediator, hence not incorporating the dialogic requirement fundamental to mediation in the ZPD. Likewise, these authors argue that the metaphor itself is flawed, in that the removal of the scaffold - referred to as fading in the literature (Sherin et al., 2009) - is a planned event in construction, while in an educational setting, "the support sometimes falls apart rather suddenly and at inopportune times" (Swain et al., 2011, p. 26). One example is the lesson ending without time for debriefing.

On a similar note, Verenikina (2004) sees no difference between the metaphor of scaffolding and other kinds of instruction. She goes on to explain how, "when taken out of its theoretical context, scaffolding tends to be interpreted as a varier of direct instruction, which invalidates the Vygotskian idea of teaching as co-construction of knowledge..." (Verenikina, 2004, p. 11).

Along the same lines, Poehner (2010) explains that the assistance provided through scaffolding is not oriented toward development, but rather toward solving the problem or task at hand. Hence, he claims, "the teachers or tutors providing the scaffold do not intend to help learners develop new cognitive functions and pay little attention to abilities that are in the process of maturing; instead, learners are given any support that is needed to complete the current task" (p. 81). This argument is shared by other researchers such as Chaiklin (2003), who encourages readers to "find 
other terms (e.g. assisted instruction, scaffolding) to refer to practices such as teaching a specific subject matter concept, skill, and so forth" (p. 59).

In short, the rejection of the metaphor of scaffolding and its role in creating valid MLEs could be subsumed in two main arguments:

a) the apparent uni-directionality of the scaffolding act and its lack of dialogicity.

b) its apparent exclusive concern with the here-and-now and not the future potential development.

If these arguments hold true, then there would be violation of two of the main premises of MLE, and we would have to concede that scaffolding is not a form of mediation compatible with MLE. In order to explore these tensions further, it would be useful to review current conceptualizations of the metaphor (for example, Holton \& Clarke, 2006; Walqui \& van Lier, 2010) in light of the characteristics of MLE. The framework for analysis we use will look at the mediator and the mediated as participants in an interaction whose purpose is the attainment of shared goals, even if these are merely to interact. The following diagram exemplifies the framework.

Figure 1: MLE as a framework for analysis

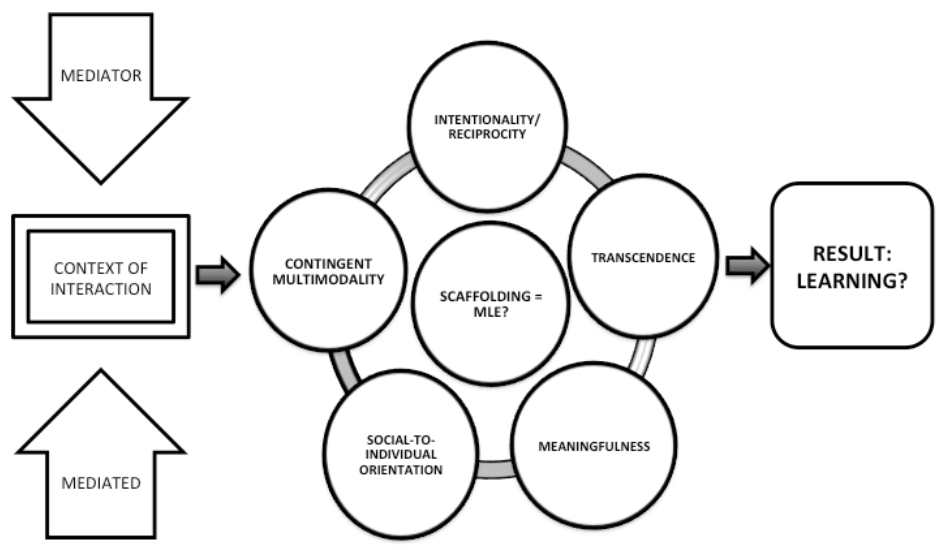

As it can be seen from the diagram, mediator and mediated engage in interaction within a particular context. That interaction is run through the filter of the characteristics of MLE and the result of the interaction is analyzed in light of current conceptualizations of the metaphor of scaffolding (Bickhard, 2005; Hammond \& Gibbons, 2005; Holton \& Clarke, 2006; Walqui, 2006). 


\section{A closer look at Scaffolding over time}

Most of the critics of scaffolding refer to the original definition proposed by Wood et al. (1976) and, in light of the wording of such definition, it could be said that their criticisms hold true in that scaffolding is depicted as nothing but an assisted form of learning. However, in that same year, Jerome Bruner and Valerie Sherwood (1976) published the results of a study involving mothers and children playing the game of peekaboo, and used the term "scaffold" to account for the interventions of the mother during the game. Surprisingly, this second conceptualization of the construct has been conspicuously absent in criticisms of scaffolding in the literature.

In their work, the authors explain how mother and child engage in playing the game, and how in doing so, the child progressively takes over some piece of the action with the mother providing scaffolds oriented toward allowing the child to take over control of the activity. Playing the game encompasses two distinct elements: a permanent structure, and the process of playing itself. The structure is made up of a rule-bound, obligatory syntax (establishing contact with the child; disappearing; reappearing; and, finally, reestablishing contact), acting as a script, which mother and child follow. While this structure remains relatively stable across cultures, there are evident variations in the process. These are the scaffolds that stem specifically from the mother's response to the child's actions during the game. The authors explain: "It is to [the child's] initiatives that the mother often responds... as if to control the child's activation. This part of the game is characteristically 'non-rule bound' and seems to be an instance, rather, of the mother providing a scaffold for the child" (Bruner \& Sherwood, 1976, p. 280).

This second and important conceptualization of scaffolding establishes a very relevant contrast with the original definition, in that the arguments of uni-directionality and focus on the present lose their validity. In the aforementioned game, mother and child engage in sustained mutual interaction and the mother's reaction to the child's behavior is intended to hand over the control of the game to the child. It is this second view of scaffolding we will look at, since it is the one adopted as the basis for continued reflection on the metaphor by current researchers.

For example, extrapolating the same characteristics of scaffolding to account for how it applies to general learning situations, Holton and Clarke (2006) provide an updated definition of the metaphor as "an act of teaching that (i) supports the immediate construction of knowledge by the learner; and (ii) provides the basis for the future independent learning of the individual" (p. 131). Along the same lines, Walqui and van Lier (2010) conclude that "the real power of scaffolding lies not in the setup... of a task... but in the... moments of agency when the child introduces something new and, perhaps unexpected... a learner's agency is promoted by gradual handover of the task to the learner" (p. 20).

Just as it was the case with Vygotsky's theory of mind, which was left incomplete as a result of his premature demise, the metaphor of scaffolding has remained an object of elaboration and research as a valid form of mediation, particularly in the field of general education. The analysis will now turn to contrasting recent conceptualizations 
of scaffolding with the elements of MLE, both in the general education field and in foreign/second language teaching.

\section{Intentionality/Reciprocity}

Scaffolding is a purposeful action that a more knowledgeable other brings about in the course of an activity, so that the less knowledgeable peer can progressively gain control over it. In this sense, the adult or expert intentionally represents the cognition of the novice in his/her cognition and provides those progressive supports that would allow the novice to gain higher levels of mastery. These, when internalized, would result in more independent performance by the novice. So, the starting point of the intentional intervention of the expert is the point at which he/she meets the novice's actual level of competence with scaffolds aligning themselves with the expert performance the adult or peer is capable of achieving.

In the field of general education, intentionality takes the form of planning for learning, which Sharpe (2006) has termed "designed-in" (p. 213) scaffolding. This designed-in scaffolding encompasses, among other things, the identification of learning goals, the organization of the classroom, and the selection and sequencing of tasks (Hammond \& Gibbons, 2005). In this dimension, the teacher operates from his/her own ideation of the learners' cognitions and performs various strategic preparations for the encounter with the learners. Taken in isolation, this designed-in scaffolding bears no difference to "good teaching" and possesses a high level of unidirectionality, in that there is no active involvement of the learner in the setup of the scaffold. The intentionality lies mostly with the teacher, and it carries with it the potential to become just another form of direct instruction.

As Sharpe (2006) points out, this designed-in scaffolding depicts only the macro level. However, there is a second dimension that we should pay attention to, and that is the actual enactment of scaffolding (Hammond \& Gibbons, 2006) where the designed-in components are put at stake in purposeful interaction with the learners. It is at this second, micro level that the actual scaffolding action occurs.

This depiction of the scaffolding process is aligned with the concepts of structure (the designed-in macro level) and process (the interactional, micro level) proposed by Bruner and Sherwood (1976). Learner intentionality and the ensuing reciprocity appear only at the micro level, because it is at that level that the teacher properly acknowledges the learners' agency. Agency stems from involvement in collaborative activity through a process of apprenticeship (Walqui \& van Lier, 2010). The designed-in tasks serve as the turf for collaborative activity, but the actual interaction imbues the tasks with the required element of reciprocity. As Shrum and Glisan (2010) explain, "... the teacher's role is (1) to recognize that assistance is contingent on what the novice is doing, not on what the expert thinks should be done, and (2) to know when to turn the task over to the novice for solo performance" (p. 26).

Referring to foreign/second language teaching in particular, Hammond and Gibbons (2005) exemplify both the intentionality and reciprocity of scaffolded 
action by citing the micro-level example of the appropriation of contributions. In language teaching, the term "appropriation" refers to the taking up of the teacher's discourse or other tools by the students in order to fulfill their own purpose. In the scaffolded interactions identified by the authors, the teachers also appropriated students' contributions with the purpose of recasting or reshaping those contributions toward the intended level of competence, which led the authors to conclude that, "through this process, the student becomes a co-participant in the construction of a broader and more systematic codification of ideas and subject-specific discourse" (Hammond \& Gibbons, 2005, p. 22).

Under this light, we can observe that scaffolding interactions containing both macro (designed-in) and contingent (micro) dimensions seem to comply with the requirements of intentionality and reciprocity of an MLE. But the micro and macro dimensions cannot just operate in isolation. It is in the systemic interplay of the designed-in and interactional scaffolds that the move to a higher level of performance can be achieved, thus underscoring the fact that the interactional level is the true level of scaffolding (Hammond \& Gibbons, 2005) and that the main purpose of the designed-in (structure) element is to facilitate the process.

\section{Transcendence}

Closely tied to intentionality and reciprocity is the fact that scaffolded interaction must help the learner go beyond the here-and-now, thus taking a further step in their learning. This characteristic of MLE has cultural implications as well, in that at the core of MLE lies the intention of making the past and present accessible to the novice so that a future can be realized. Citing models of construction of the future in developmental psychology, Poehner and Lantolf (2005) explain that Sociocultural Theory constitutes a present-to-future model whose aim is "to increase the distance between the past and the present, while at the same time decreasing the distance between the present and the future... Present to future models, then, predict the future not a priori but on the basis of concrete mediated activity" (p. 237).

In this respect, Holton and Clarke (2006) explain how one of the objects of teachers' activity is the creation of the "epistemic student (that is, the student as constructor of knowledge)" (p. 127). In their view, scaffolding anticipates acts of constructions in that the scaffolded interactions allow for the immediate construction of knowledge on the part of the student. This knowledge, in turn, will act as the foundation for the student's future elaboration of the topic or problem. This leads these authors to conclude that scaffolding "is not an act of closure" (Holton \& Clarke, 2006, p. 131).

In Bruner and Sherwood's (1976) conceptualization, the control exerted by the expert over the structure allows for the stimulation of the child to take over control of the activity. It is when the child shows some sign of being able to take control that the scaffold is put in place, by handing over particular aspects of the action (or even the complete action) and guiding the child's accomplishment. In this sense, control is 
shared. If we extrapolate this to a classroom situation, we can see how the designed-in scaffolding is oriented toward the future (through curriculum goals, for example) and acts as the structure for interaction, which will result in further learning.

Transcendence as a distinguishing feature of MLE also purports a cultural reproduction purpose. This implies a requirement for continuity and coherence as central features, which allow access to the past in the present with a view toward the future. Classrooms are part of the socially created tools of education that serve this specific cultural reproduction purpose. As Walqui and van Lier (2010) explain, "a classroom has rituals that characterize it and keep it together, some that stay constant and others that vary and evolve... Within these recurring, stable aspects of the classroom, learners find stability, as well as opportunities to innovate and take initiative" (pp. 34-35).

These same authors explain how the designed-in, stable scaffolds allow learners to innovate, thus imbuing the interaction with the unpredictability that constitutes the basis of micro scaffolding. To these, the teacher will respond in a "proleptic" (Walqui \& van Lier, 2010, p. 24) way, foreshadowing the future in the present. In other words, the teacher operates on the assumption that students have abilities they do not really have, but this future-oriented belief is an essential condition for the development of those activities.

Transcendence, then, is both a requirement for and a consequence of scaffolding. A ZPD can surface only when interactional moves allow for the designed-in structure to be affected in a dialectical way by the teacher handing over and the student taking over control of the activity. In LT, for example, transcendence can be located in the teacher's scaffolds that help the learner move from their interlanguage toward the required linguistic norm.

\section{Meaningfulness}

While intentionality and reciprocity give rise to transcendence, none of these characteristics of MLE can operate effectively in a scaffolded situation unless it is meaningful. In Bruner and Sherwood's (1976) ideation of the metaphor of scaffolding, meaning is not only an a priori condition, but also an ongoing process of negotiation in which mother and child actively search for mutual clues in order to bridge a gap between comprehension and production.

This has a number of relevant implications. For a start, the vehicle for the coconstruction of meaning is found in the designed-in structural element of the task (intentional and future-oriented), while the co-construction actually happens during the interactive phase (reciprocal and future-oriented). It is here that contingent scaffolds are put in place as a result of the give-and-take of control over the task, thus helping the learner move from comprehension to production. However, a prerequisite condition for this to happen is that the structure be made comprehensible to the novice. This is achieved by maintaining the task constant, thus allowing for iterative approximations by both teacher and learner, and not by simplifying the task in such a way that the learner is only able to act upon it from imitation, thus failing 
to gain control over it.

The simplification alluded to by Wood et al. (1976) in their original definition of the metaphor gave rise to the notion that scaffolding is mainly concerned with helping the novice solve a task at hand, but not with promoting learning leading to development. In other words, the inclusion of the term "simplification" in the original definition put the solution of the task as the horizon for the interaction, whereas an MLE's horizon is the potential development of the child in light of his perceived current capacities.

Bliss et al. (1996) point out that for the gap between comprehension and production to be breached, the task must remain constant during the learning interaction. They say that "in order for a new skill to be acquired it must be comprehensible, even though it has not yet been produced" (p. 39). The required simplification, if any, is not in the task but in the role the learner plays in the task.

Making the scaffolded interaction meaningful also means that participants "language" with each other (Swain et al., 2011, p. 34) - that is to say, they actively shape and reshape language as support for their evolving understanding of their role in the activity. Sometimes, humans "language" with others as a form of shared cognition, particularly during highly interactive contingent scaffolding instances, whereas at other times they use private speech (in the form of thinking or thinking aloud) to articulate their current understanding to themselves, as well as others.

This brings to bear the role that feedback plays in scaffolding interactions. In direct instruction, the typical sequence of interaction is what has been called IRF (Initiation-Response-Feedback). While the IRF sequence has gained ill repute because of its transmission orientation, when seen under the light of the scaffolding metaphor, the third element acquires a transformational power. According to Hammond and Gibbons (2005), whenever a teacher asks for clarification, probes students' responses, or requests elaboration or explanation, he [sic] is "increasing the prospectiveness" ( $\mathrm{p}$. $24)$ - that is, opening up the discourse, thus affording learners more interactional opportunities to engage in longer, more productive meaning-making.

In LT, the increase of prospectiveness is a particularly relevant aspect of MLE since language is one of the most important psychological tools in the development and mediation of action. Hence, it stands to reason that the feedback teachers provide to learners needs to allow for the extension of the interaction and should be based on meaning.

\section{Contingent multimodality}

While language is the prime tool for scaffolding, it is not the only semiotic tool that teachers can use in scaffolding learners' understanding. Contingent multimodality refers to the use of alternative semiotic tools in order to mediate understanding. The use of the two terms in this paper has a particular intention. Contingency, in the context of scaffolding, is understood as "the way an adult judges the need and quality of assistance required by the learner on the basis of moment-to-moment understanding" 
(Gibbons, 2003, p. 267). However, when language cannot provide the assistance required, adults consciously resort to other semiotic tools so that assistance can be provided. In LT, the norm is to use contingent multimodality - the confluence of various semiotic tools - whenever teachers mediate students' understanding. Thus, teachers' use of the target language is generally accompanied by gestures, visuals, or changes in stress and intonation, for example.

In the literature on scaffolding, contingent multimodality is extensively validated. For example, Hammonds and Gibbons (2005) explain how, in the context of their research, "...the use of other semiotic systems not only supported students' comprehension, but also in themselves constructed meaning" (p. 16).

Gibbons (2003) concept of message abundancy explained earlier reinforces the idea that the use of various semiotic systems can grant access to similar information from a variety of sources. Examples cited included graphs, maps, diagrams, photos, and symbols.

Holton and Clarke (2006) explain how metacognition can also be counted as an alternative semiotic system in that scaffolds can take two distinct forms. One of these forms is conceptual, which is language-based and explicit or cognitive. In contrast, access to their metacognition allows learners to access heuristics that can scaffold their involvement in tasks similar to others they have experienced, but that they cannot yet solve on their own.

\section{Social-individual orientation}

The fact that scaffolding is a way to help novices gain control over tasks with the purpose of prompting their future autonomous performance has been made sufficiently clear so far in this paper. However, there are subtle aspects of this characteristic of MLE that deserve particular attention, since they impinge on the systemic definition of MLE advocated for here.

The designed-in elements of scaffolding are perhaps the most obvious example of the social-individual orientation. Just as is the case with the ritual game of peekaboo, curriculum plans provide a socially determined structure for the interaction. What these plans determine is the knowledge, skills, and dispositions expected of members of that society.

Next, comes the sine qua non requirement to involve learners in the learning task so that their learning can be scaffolded, since it is only after learners are involved in the task that contingent scaffolding can take place.

Finally, once the interaction is in place, the externalization of internal dialogues for mutual appropriation becomes a major resource for the development of thinking, and with it comes an enhancement of metacognition and its subsequent possibility for the learner to become more autonomous as a result of learning. Furthermore, control over one's metacognitive awareness can help fill gaps in knowledge. As Holton and Clarke (2006) conclude "...the student who cannot make a contribution of content can certainly be encouraged to make one of heuristics and teachers should encourage 
such contributions" (p. 142).

\section{Implications and potential directions}

From the discussion above, it would appear that criticisms of scaffolding as a valid form of mediation do not actually stand to reason, as scaffolding embodies all the characteristics of MLE. The same discussion gives rise to a series of key concepts useful in repositioning the metaphor of scaffolding.

First, the requirement of intentionality in MLE brings the issue of agency (Walqui \& van Lier, 2010) to the forefront and beckons the notion that there may be other forms of scaffolding besides those afforded by teachers. In this view, teachers exercise agency in preparing for instruction through planning. Thus, the designed-in element sets the stage for the interaction, which, in turn, allows the enactment of contingent scaffolds. When learners exercise their agency, they also provide one another with scaffolds, both designed-in (through metacognitive engagement) and contingent (through interaction with their peers). This notion of agency, understood as the purposeful engagement in and with learning, opens the door for self- and peerscaffolding (Holton and Clarke, 2006). In this scenario, learners take a much more active role and teachers become designers of learning opportunities and assessors of learner development. However, it should be noted that it is only when the designedin and the contingent elements are present that true scaffolding can occur. In other words, designed-in and contingent scaffolds, in and of themselves, are not enough. They need to be operationalized in a systemic fashion.

This also points to the realization that additional forms of scaffolding derived from learners exercising their agency give rise to contingent multimodalities as divergent and productive as "languaging" (Walqui \& van Lier, 2010) with one another and their teachers, or the development of metacognition (Sherin, et al., 2009). In either of these scenarios, the different contingencies (self-, peer-, and expert scaffolding) allow for actual negotiation and reification of new meanings, derived from learners interacting with their own metacognition and the shared cognition co-constructed with peers and with the teacher, as well as from providing and receiving timely feedback that helps them bridge the gaps between their actual and intended performance.

When teachers and learners engage in reciprocal interaction oriented toward development, then careful diagnosis of the here-and-now and evidence-based change are a requirement. This can only be possible if both assessment and feedback are purposefully and usefully sought and given. In this renewed view of scaffolding, assessment guides teaching in much the same way as learning guides development: with teaching lagging behind assessment in an adaptive, albeit reactive, way. This allows the teacher to be truly proleptic in the enactment of his or her designed-in and contingent scaffolds. In this respect, Poehner (2010) stresses the need for ongoing, proactive assessment to be built into all teaching and learning activities in such a way that learners can identify gaps in understanding and receive supports that help them 
fill those gaps.

The proleptic role of the teacher also brings to the forefront the issue of transcendence. For students to learn and thus develop, contingent scaffolds need to be developed and enacted that make explicit for both teacher and learners what future performances should look like. Hence, learning targets or standards need to be unpacked by teachers and learners so that a clear picture of the development horizon is painted. In this process, the quality of feedback sought and given plays a key role in outlining that horizon. This also highlights the need for differentiating instruction so that diverse learners can receive diverse scaffolds according to their need.

Both for language teaching and general education, this means that scaffolding is not just good teaching (understood as careful planning followed by skillful delivery). Good teaching is mostly concerned with the designed-in elements, while scaffolding "is specific help that provides the intellectual 'push' to enable students to work at the 'outer limits of the ZPD”' (Hammond \& Gibbons, 2005, p. 25).

However, it should be stressed at this time that effective scaffolding needs to embody all the requirements of an MLE in order to have the potential to result in enhanced student learning. In this light scaffolding, even when principled, is a highly situated and contextually constrained activity and, as such, only bears the potential to result in learning gains for the learner. It takes a teacher who becomes truly engrossed in dialectical interactions with the learner to be able - through trial and error, intention, and contingency - to provide effective scaffolding. This last acknowledgement also points to the fact that the role of the teacher needs to be reconfigured within a Sociocultural Perspective to stray away from the notion of expert to that of a learner of teaching (Johnson, 2009).

Such a positioning would allow teachers to engage in inquiry on learning by carefully assessing learners' progress toward goals. This sort of inquiry would involve teachers in finding out novel ways to support learning and can derive in situated, purposeful professional development. In short, by conceiving of themselves as learners of teaching, teachers focus their activity on the future of their students and thus become life-long learners.

All these points beckon the need to revisit the principles that guide current teacher education practices so that teacher preparation is better able to address the formation of professionals who have the knowledge, skills, and dispositions necessary to promote scaffolding through their interaction with students. The current dismal learning results in most countries in the world and the high attrition experienced by the teaching profession both seem to indicate that validating the metaphor of scaffolding as a form of mediation in the ZPD will require a re-examination of the way teaching and learning are currently being enacted. In this respect, it would seem that at least a re-examination of the roles of planning, assessment, and feedback on student learning are in order. 


\section{Notes}

1. The role of content should be elaborated, taking into account an age differential. While during childhood the availability of MLE seems to exert the greatest impact, Feuerstein et al. (1980) point out that "in adult life differences in content exert greater influence on the development of cognitive process" (p. 23). This may point at a potential fallacy in trying to apply this construct to situations where participants in the activity are not children.

\section{References}

Bickhard, M. (2005). Functional scaffolding and self-scaffolding. New Ideas in Psychology, 23, 166-173.

Bliss, J., Askew, M., \& Macrae, S. (1996). Effective teaching and learning: Scaffolding revisited. Oxford Review of Education, 22(1), 37-61.

Bruner, J., \& Sherwoord, V. (1976). Peekaboo and the learning of rule structures. In J. Bruner, A. Jolly, \& K. Sylva (Eds.), Play: Its role in development and evolution (pp. $277-$ 287). Harmondsworth, England: Penguin Books.

Chaiklin, S. (2003). The Zone of Proximal Development in Vygotsky's analysis of learning and instruction. In A. Kozulin, B. Gindis, V. Ageyev, \& S. M. Miller (Eds.), Vygotsky's educational theory in cultural context (pp. 39-64).Cambridge, England: Cambridge University Press.

Chamot, A. U. (2009). The CALLA Handbook: Implementing the Cognitive Academic Language Learning Approach (2nd ed.). New York, NY: Pearson.

Feuerstein, R., Rand, Y., Hoffman, M., \& Miller, R. (1980). Instrumental enrichment: An intervention program for cognitive modifiability. Baltimore, MD: University Park Press.

Freeman, D. (1993). Renaming experience/reconstructing practice: Developing new understandings of teaching. Teaching and Teacher Education, 94, 485-497.

Gibbons, P. (2002). Scaffolding language, scaffolding learning: Teaching Second Language Learners in the mainstream classroom. Portsmouth, NH: Heinemann.

Gibbons, P. (2003). Mediating language learning: Teacher interactions with ESL students in content-based classrooms. TESOL Quarterly, 37(2), 247-273.

Hammond, J., \& Gibbons, P. (2005). Putting scaffolding to work: The contribution of scaffolding in articulating ESL education. Prospect, 20(1), 6-30.

Holton, D., \& Clarke, D. (2006). Scaffolding and metacognition. International Journal of Mathematical Education in Science and Technology, 37(2), 127-143.

Johnson, K. E. (2009). Second language teacher education: A sociocultural perspective. New York, NY: Routledge.

Kozulin, A. (1998). Psychological tools: A sociocultural approach to education. Cambridge, MA: Harvard University Press.

Mason, J. (2002). Researching your own practice: The discipline of noticing. London, England: Routledge.

Poehner, M. E. (2010). Dynamic assessment: A Vygotskian approach to understanding and 
promoting L2 development. Berlin, Germany: Springer.

Poehner, M. E., \& Lantolf, J. P. (2005). Dynamic assessment in the language classroom. Language Teaching Research, 9(3), 233-265.

Sharpe, T. (2011). "Unpacking” scaffolding: Identifying discourse and multimodal strategies that support learning. Language and Education, 20(3), 211-231.

Sherin, B., Reiser, J., \& Edelson, D. (2009). Scaffolding analysis: Extending the scaffolding metaphor to learning artifacts. Journal of the Learning Sciences, 13(3), 387-421.

Shrum, J. L., \& Glisan, E. W. (2010). Teacher's handbook: Contextualized language instruction. Boston, MA: Heinle Cengage Learning.

Swain, M., Kinnear, P., \& Steinman, L. (2011). Sociocultural theory in second language education: An introduction through narratives. Bristol, England: Multilingual Matters.

Verenikina, I. (2004). From theory to practice: What does the metaphor of scaffolding mean to educators today? Outlines, 2, 5-15.

Vygotsky, L. S. (1978). Mind in society: The development of higher psychological processes. Cambridge, MA: Harvard University Press.

Vygotsky, L. S. (1986). Thought and language. Cambridge, MA: The MIT Press.

Walqui, A. (2006). Scaffolding instruction for English Language Learners: A conceptual framework. International Journal of Bilingual Education and Bilingualism, 9(2), 159-180.

Walqui, A., \& van Lier, L. (2010). Scaffolding the academic success of adolescent English Language Learners. San Francisco, CA: WestEd.

Willis, J. (1996). A framework for Task-based Learning. Harlow, England: Longman.

Wood, D., Bruner, J., \& Ross, G. (1976). The role of tutoring in problem solving. Journal of Child Psychology and Psychiatry, 17, 89-100. 